\title{
Failure to Engage in Breast Screening and Risk Assessment Results in More Advanced Stage at Diagnosis
}

\author{
Alison Johnston, Sharon Curran, Michael Sugrue* \\ Breast Centre North West, Letterkenny Hospital, Donegal Clinical Research Academy, Donegal, Ireland \\ Email: ${ }^{*}$ michael.sugrue@hse.ie
}

Received 4 March 2015; accepted 6 April 2015; published 9 April 2015

Copyright (C) 2015 by authors and Scientific Research Publishing Inc.

This work is licensed under the Creative Commons Attribution International License (CC BY).

http://creativecommons.org/licenses/by/4.0/

(c) (i) Open Access

\section{Abstract}

Background: Although well established, population based screening and family risk assessment for breast cancer have come under increasing scrutiny. The concept of over diagnosis is increasingly cited in cancer publications. This study assessed the impact of failure to screen or risk assess patients attending with a new diagnosis of breast cancer. Methods: A retrospective review was undertaken of 200 consecutive patients diagnosed with breast cancer between January 2010 and September 2012 at Letterkenny Hospital. Appropriate screening was defined as biennial in those aged 50 - 66 and in those 40 - 49 with moderate/high family history risk (NICE criteria or IBIS criteria). Patient demographics, screening history, diagnosis date and stage (TNM) were documented. Patients with previous breast cancer were not included $(n=17)$. Results: 200 consecutive patients, whose mean age was 61 (range 28 - 99), were studied. 112/200 (56\%) met no criteria for screening or family history assessment, and $88 / 200(44 \%)$ met criteria for either screening (in 56) or family history assessment (in 32). 61/88 (69.3\%) meeting criteria did not have a mammogram or risk assessment. The stage of breast cancer was significantly earlier in those screened appropriately, with early stage cancer in $n=111 / 139(79.9 \%)$ and late in $n=28 / 139(20.1 \%)$, compared with $38 / 61(62.3 \%)$ and $23 / 61(37.7 \%)$ in those failing to be screened appropriately $\left(p=0.01 \chi^{2}\right.$ df1). Conclusion: Failure to engage in breast screening and risk assessment resulted in more advanced stage at diagnosis.

\section{Keywords}

Breast Cancer, Breast Cancer Detection, Breast Screening, Breast Outcomes

\footnotetext{
${ }^{*}$ Corresponding author.
}

How to cite this paper: Johnston, A., Curran, S. and Sugrue, M. (2015) Failure to Engage in Breast Screening and Risk Assessment Results in More Advanced Stage at Diagnosis. Advances in Breast Cancer Research, 4, 53-62. 


\section{Introduction}

Over the last decade, there has been significant global reduction in mortality in breast cancer [1]. Early detection of breast cancer optimizes outcomes and survival [2]-[5]. This is facilitated by appropriate breast screening and triage of women of increased risks [6]. While it is universally accepted that breast screening increases breast cancer survival, recent heated discussions question whether it reduces breast cancer mortality [7]-[9]. It has even been suggested that breast screening be abandoned [10]. The concept of over diagnosis and harm of screening and risk assessment has been highlighted [11] [12]. Current international guidelines suggest that women with a moderate or greater family history breast cancer risk should have a mammogram from the age of 40 . Those between 50 and 65 should be enrolled in breast screening [13]-[15].

The uptake rates of utilization of existing screening programs are influenced by socioeconomic factors, ease of access, advertising and public awareness. However, not all studies show a positive relationship between familial breast cancer risk and mammographic uptake [16] [17]. There has been a lack of published data assessing enrolment and uptake of breast screening and risk assessment in patients with a known family history risk and or those of breast screening age who should have undergone breast screening [18]. Some countries, such as Ireland and Estonia, have higher breast cancer mortality than the European on average. This is a multifactorial issue with many potential explanations including public awareness, organization and access to services as well as treatments employed. Understanding the stage of presentation of breast cancer may identify opportunities to improve outcome [1]. It is clear, however, that tumor size at presentation predicts long term survival [19].

This study assessed uptake of breast screening and compliance with risk assessment in patients, either with a familial breast cancer history or those meeting screening age criteria in patients presenting with a new index breast cancer.

\section{Methods}

An ethically approved retrospective review of 200 consecutive newly diagnosed breast cancer patients, presenting to the Symptomatic Breast Unit of Letterkenny Hospital between January 2010 and September 2012, was undertaken. Patients with a known previous diagnosis of breast cancer were excluded from the study $(n=17)$. Letterkenny Hospital is a designated provider of multidisciplinary breast cancer care under the Irish National Cancer Control Program (NCCP, 2007), working as a satellite centre of its parent cancer centre at University College Hospital Galway [20]. Breast screening in Ireland commenced in 2000 in Dublin and spread nationally throughout the country having arrived in the North West (where this study took place) in October 2009 [13]. Open access or family doctor referral for non-screening mammography is not available for asymptomatic women.

The cohort was divided into one of two groups; the appropriately screened group or the inappropriately screened group. Appropriate screening for the study was defined as biennial in those of breast screening age $(50-65$ years old) [13]. Biennial mammography was considered optimal in those aged 40 - 49 who met 2006 NICE criteria for a moderate family history risk or had an IBIS (Tyrer-Cuzick) $10 \mathrm{yr}$ risk $>3 \%$ or a lifetime risk $\geq 17 \%$ [15] [21]. Appropriate screening and assessment was deemed to have occurred if a mammogram had been performed within 2 years of diagnosis. Low-risk patients outside breast screening age were also deemed to have been appropriately screened with no previous mammogram performed.

Inappropriate screening and assessment was deemed to have occurred if a mammogram had not been performed within 2 years of diagnosis in those of breast screening age and /or having a moderate or high family history risk.

Patient demographics, date of diagnosis, stage and previous visits to a breast clinic were documented. TNM staging was used to classify stage at presentation [22]. Those stages $0-2$ were deemed to be early stage and those stages 3 - 4 late stages. A second clinically focused staging system was also used classifying stage as localised, loco-regional or distant. Localised was T0-3 N0 M0; loco-regional was T0-3 N1-3 M0 or T4 N any M0 and distant was T any N any M1 [2]. Data was retrospectively extracted from prospectively entered medical records and hospital databases. Patients were not contacted to determine a reason for non screening to avoid creating anxiety or distress.

Breast cancers detected through the National Screening Programme were not included in this study as they are processed through a standalone breast screening service. In the study period we estimate that 11,822 women were screened with Breast Screening in the Northwest and 137 cancers detected on what would have been a pre- 
liminary round of screening for most patients [23]. Data was expressed as mean and standard deviation for normally distributed data and medians and inter quartile range for non-normal data. Chi square test or Student's T-test was used as appropriate for categorical and continuous variables. Data was considered significantly different if $\mathrm{p}$-value was $<0.05$.

\section{Results}

200 patients, mean age $61.4 \pm 15.4$ years (range 28 - 99), all female, were studied. The age distribution is shown in Figure 1. 172/200 patients were symptomatic when diagnosed and 28/200 asymptomatic. Of the 28, 12 were incidentally identified during unrelated body imaging, 12 detected by surveillance screening for family history and 4 by other modalities. The dominant symptom at presentation is shown in Table 1.

$139 / 200(69.5 \%)$ patients were appropriately screened and 61/200 (30.5\%) inappropriately screened. Of the 200 patients, $112(56 \%)$ met no screening or family history risk assessment indication. 88/200 met criteria for mammography: 56/88 met age criteria for breast screening, 21 purely because of family history and 11 met both criteria. Of the 32 family history cohort 29 had a moderate family history risk and 3 were high risk. Of those meeting the screening and risk assessment criteria, only $27 / 88$ (30.7\%) were assessed appropriately with mammography. Of the 61 failing to meet screening targets 19 (31.1\%) were in the family history risk group and 42 $(68.9 \%)$ were in the breast screening group. Of those with a family history $13 / 32(40.6 \%)$ were appropriately screened and 14/56 (25\%) in the breast screening age group. 36/61 (59.0\%) never had a mammogram while the

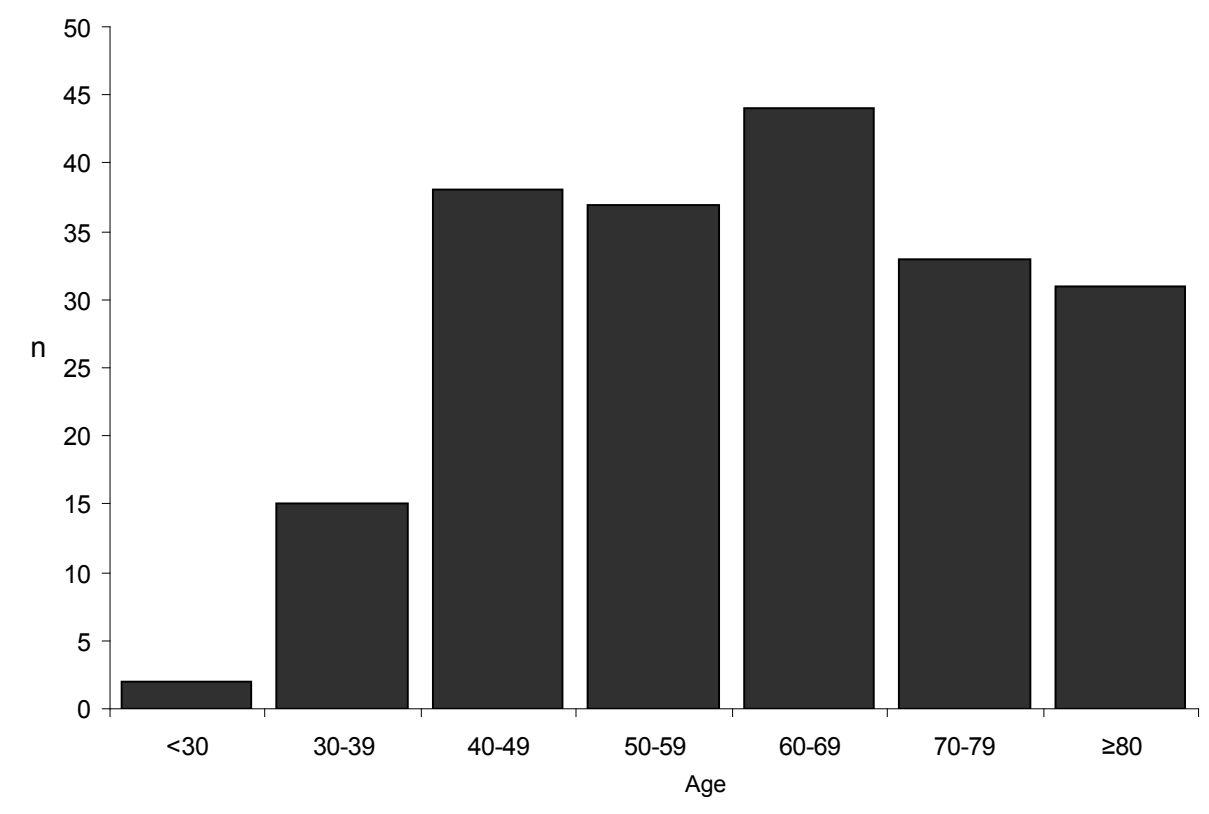

Figure 1. Age distribution of breast cancer $(\mathrm{n}=200)$.

Table 1. Dominant symptom at presentation $(n=172)$.

\begin{tabular}{ccc}
\hline Dominant symptom & $\mathrm{n}$ \\
\hline Breast lump & 125 \\
Mastalgia & 17 \\
Nipple retraction & 9 \\
Skin and nipple changes & 8 \\
Fungating breast lesion & 6 \\
Nipple discharge & 4 \\
Altered breast sensation & 3 \\
\hline
\end{tabular}


remaining 25/61 (41\%) had a mammogram performed more than 2 years pre-diagnosis. The previous mammogram was performed on average $9 \pm 7.8$ years prior to diagnosis. $26 / 61$ had attended a specialist breast clinic previously, before 2008. Failure to follow up these women was due to both system factors $n=24$ and patient factors $n=2$. System failures to review patients occurred within the family history service in $n=12$ and within the asymptomatic National breast screening services in $n=12$.

In patients with increased family risk, the mean 10 year and lifetime IBIS risk was $7.2 \% \pm 5.0 \%$ (range 2.7 29.1 ) and $18.9 \% \pm 10.5 \%$ (range $6.4-61.4$ ) respectively. The BCRA 1 and 2 risks were low for this sub group, at $1.2 \% \pm 3.6 \%$ (range $0-17.1$ ) and $0.5 \% \pm 1.1 \%$ (range $0-5.8$ ) respectively. 24 patients in total met NICE criteria for secondary care referral to family history clinics and only one for tertiary care referral to genetic services.

88 of the 200 (44\%) had previously attended the breast unit; their first attendance was a median of 84 months prior to the date of diagnosis (range 2 - 408). No cancer was considered a missed diagnosis. Interval cancers were detected in 18 (9\%) ( $\leq 24$ months), 11 of these being $\leq 12$ months. One had a delay of 10 months from initial presentation to final diagnosis. Interval cancers were detected a mean of $10.6 \pm 4.7$ months (range $2-20$ ) after the last mammogram. The pathology of the interval cancers were invasive ductal $n=11$, DCIS $n=4$ and lobular $n=3$.

Of the $82 / 200(41 \%)$ who had had a previous mammogram, the interval between the last mammogram and the current diagnostic mammogram was on average 58.4 months \pm 61.3 (range 1 month to 312 months). The number of years from previous mammogram to diagnosis is shown in Figure 2. The cancers were mammography occult in $4 / 200$, three in the appropriately screened group and one in the inappropriately screened group. Mammograms were not performed in three patients, due to tumour ulceration in two and immobility in one.

The appropriateness of screening and risk assessment within each age bracket is shown in Figure 3. The appropriate group $(\mathrm{n}=139)$ were older with a mean age of $63.4 \pm 17.5$ years $(28-99)$ compared to the inappropriately screened group $(\mathrm{n}=61) 56.7 \pm 7.2(42-66)(\mathrm{p}=<0.01)$.

\section{Tumour Pathology and Stage}

DCIS was diagnosed in $n=21$ and invasive tumours in $n=179$. Tumour stage across all 200 patients is show in Table 2. Overall T3 and T4 tumour occurred in $14.4 \%$ of the appropriately screened group compared to $24.6 \%$ of those inappropriately screened $(\mathrm{p}=0.08)$. The mean invasive tumour size $(\mathrm{n}=179)$ is shown in Table 3 .

$107 / 200(53.5 \%)$ were N0, 54/200 (27\%) N1, 17/200 (8.5\%) N2, 13/200 (6.5\%) N3 and nodal status was unknown in $9 / 200(4.5 \%)$. In the appropriately screened group 59/139 (42.5\%) were nodal positive and in the inappropriately screened group this was $34 / 61(55.7 \%)\left(\mathrm{p}=0.08 \chi^{2} \mathrm{df1}\right)$.

$21 / 200(10.5 \%)$ were diagnosed at stage $0,41 / 200$ (20.5\%) stage I, 86/200 (43\%) stage II, 28/200 (14\%) stage III and 24/200 (12\%) stage IV. TNM stage of presentation for the two groups is shown in Table 4. In the appropriately screened group 81/139 (58.3\%) had local disease, 45/139 (32.4\%) loco/regional disease and 12/139 $(8.6 \%)$ distant disease. $1 / 139(0.7 \%)$ was not completely staged due to CT phobia. In the inappropriately screened

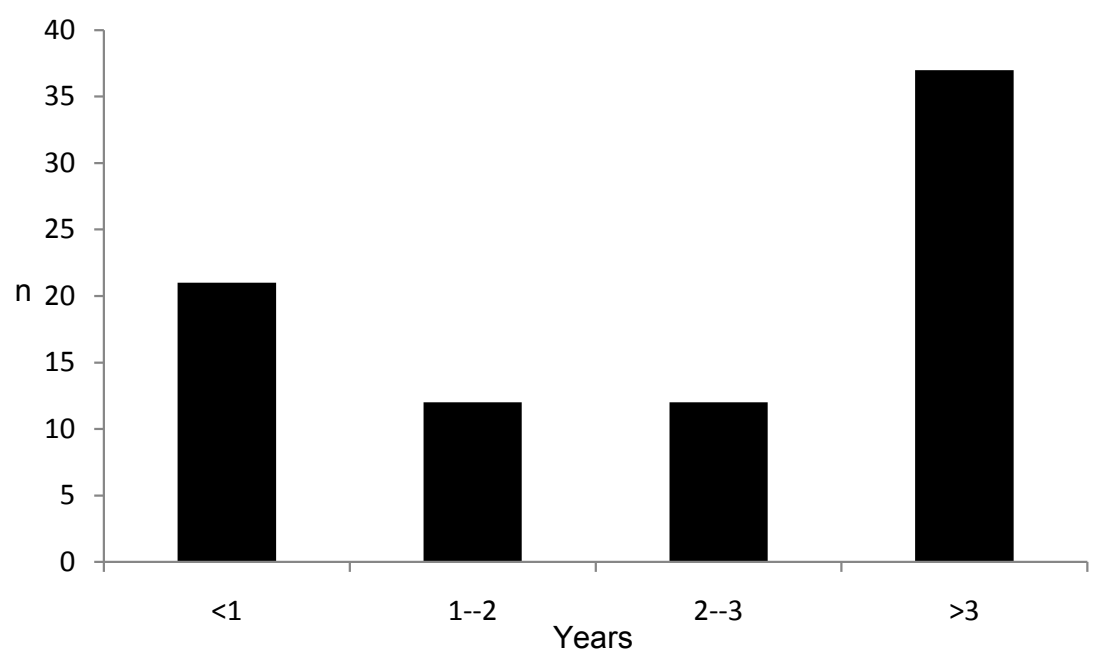

Figure 2. Years from previous mammogram to diagnosis $(n=82)$. 


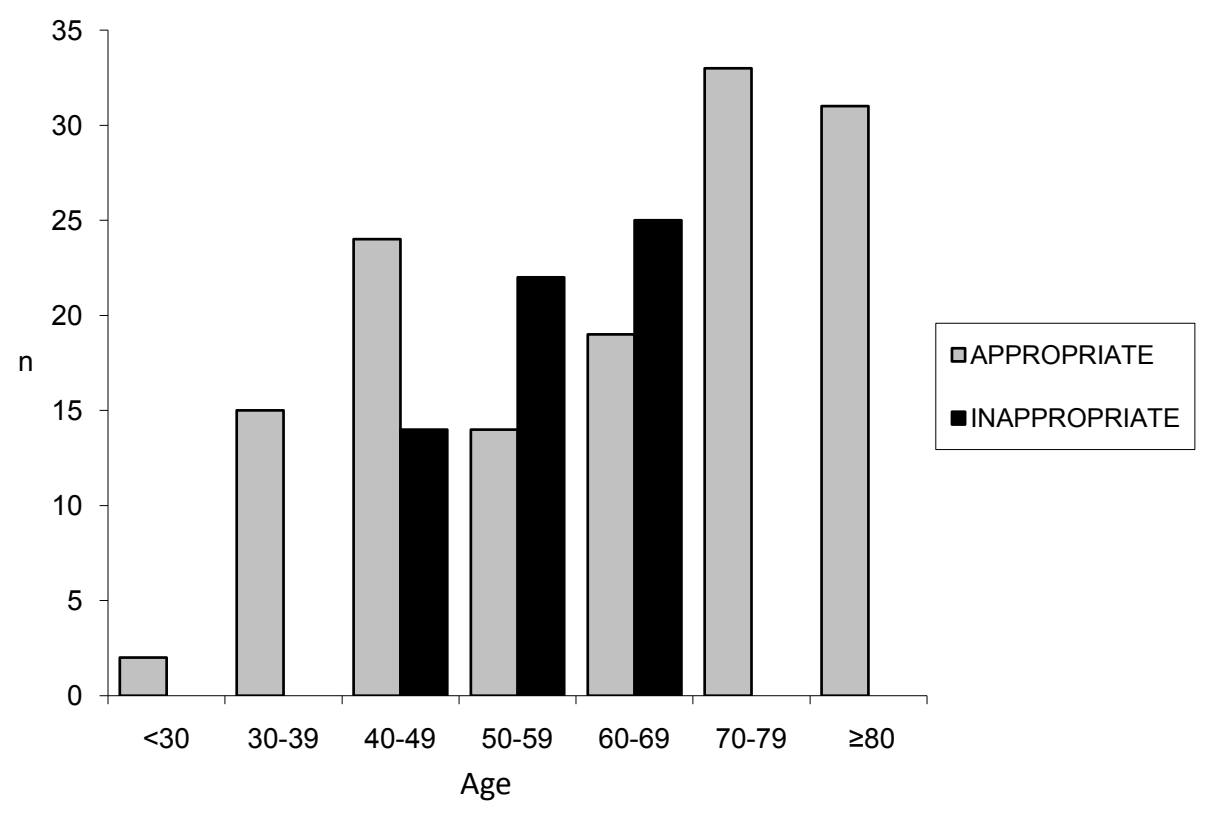

Figure 3. Appropriateness of screening and risk assessment according to age $(n=200)$.

Table 2. Tumour stage across all 200 patients.

\begin{tabular}{ccccc}
\hline & \multicolumn{2}{c}{ Appropriately screened $(\mathrm{n}=139)$} & \multicolumn{2}{c}{ Inappropriately screened $(\mathrm{n}=61)$} \\
\hline Tumour stage & $\mathrm{n}$ & $\%$ & $\mathrm{n}$ & $\%$ \\
\hline Tis & 13 & 9.3 & 8 & 13.1 \\
T1 & 41 & 29.5 & 15 & 24.6 \\
T2 & 65 & 46.8 & 23 & 37.7 \\
T3 & 14 & 10.1 & 7 & 13.1 \\
T4 & 6 & 4.3 & & 11.5 \\
\hline
\end{tabular}

$(\mathrm{p}=0.25)$

Table 3. Invasive tumour size $(\mathrm{mm})(\mathrm{n}=179)$.

\begin{tabular}{cccc}
\hline Stage $(\mathrm{TNM})^{*}$ & All invasive tumours $\mathrm{n}=179$ & Appropriately screened $\mathrm{n}=126$ & Inappropriately screened $\mathrm{n}=53$ \\
Early & $\mathrm{n}=128$ & $\mathrm{n}=98$ & $\mathrm{n}=30$ \\
& $24.1 \pm 14.1(0.8-105)$ & $24.5 \pm 15.3(0.8-105)$ & $\mathrm{n}=23$ \\
Late & $\mathrm{n}=51$ & $\mathrm{n}=28$ & $50.9 \pm 29.9(11.6-120)$ \\
\hline
\end{tabular}

${ }^{*}$ TNM stages $1-2$ were deemed to be early stage and stages 3 - 4 late stage.

Table 4. TNM stage of breast cancer at presentation.

\begin{tabular}{|c|c|c|c|c|c|c|}
\hline & \multicolumn{2}{|c|}{ All } & \multicolumn{2}{|c|}{ Appropriately screened } & \multicolumn{2}{|c|}{ Inappropriately screened } \\
\hline & \multicolumn{2}{|c|}{$\mathrm{n}=200$} & \multicolumn{2}{|c|}{$\mathrm{n}=139$} & \multicolumn{2}{|c|}{$\mathrm{n}=61$} \\
\hline Stage $(\mathrm{TNM})^{*}$ & $\mathrm{n}$ & $\%$ & $\mathrm{n}$ & $\%$ & $\mathrm{n}$ & $\%$ \\
\hline Early & 149 & 74.5 & 111 & 79.9 & 38 & 62.3 \\
\hline Late & 51 & 25.5 & 28 & 20.1 & 23 & 37.7 \\
\hline
\end{tabular}

p-value $0.01 \chi^{2} \mathrm{df}=1$. ${ }^{*}$ TNM stages $0-2$ were deemed to be early stage and stages $3-4$ late stage. 
group 27/61 (44.3\%) had local disease, 22/61 (36.1\%) loco/regional disease and 12/61 (19.6\%) distant disease (p-value $0.05 \chi^{2} \mathrm{df}=2$ ).

In those meeting screening criteria $(n=88)$, DCIS was diagnosed in $n=14$ and invasive tumours in $n=74$. Tumour stages for those meeting screening criteria are shown in Figure 4. The mean invasive tumour size (mm) in $n=74$ was $32.1 \pm 24.6(5-120)$. In the appropriately screened group $(n=21)$ this was $25.0 \pm 22.1(5-105)$ and in the inappropriately screened group $(\mathrm{n}=53) 34.9 \pm 25.2(5.5-120)(\mathrm{p}=0.1)$.

14 of the $88(15.9 \%)$ were stage 0 at diagnosis, $17 / 88(19.3 \%)$ stage I, 32/88 (36.4\%) stage II, $12 / 88(13.6 \%)$ stage III and $13 / 88(14.8 \%)$ stage IV. $74.1 \%$ of those appropriately screened had localised disease versus $44.2 \%$ in those inappropriately screened. $22.2 \% \mathrm{v} 36.1 \%$ had loco/regional disease and $3.7 \% \mathrm{v} 19.7 \%$ distant disease respectively (p-value $0.02 \chi^{2} \mathrm{df}=2$ ).

The time from diagnosis to surgery in 143/200 was a mean of $13 \pm 8$ days $(1-50)$ with a median of 12 . $41 / 200$ was treated without surgery; $16 / 200$ received neo-adjuvant therapy.

\section{Discussion}

Optimizing breast cancer care is a global necessity, aided by breast screening and risk assessment. Recently, however, there has been doubt cast on the value of risk assessment programmes, in particular breast screening [10] [24].

The optimal path in breast cancer care has been clouded further by variability in outcomes from different countries and healthcare services. More recently the concepts of the over diagnosis have seriously questioned the actual benefits of breast screening and risk assessment programmes.

Heated discussion has arisen in relation to the provision of balanced outcome reporting and balanced messages, to enable informed choices, for women attending breast risk assessment and screening [25]. This study has identified that failure to enrol in breast risk assessment and breast screening results in significantly later stage of breast cancer presentation.

Breast screening has developed at different times in different countries. Scandinavia, USA and the United Kingdom developed formal screening programmes between 1990 and 2006. In Ireland the Breast Check programme rolled out to the entire country in 2009. The last region for this programme to be enrolled was in Donegal in the North West of Ireland, the site of the study. Ireland has a designated regionalised breast cancer programme with 8 designated units of which Letterkenny Hospital is the provider for a population of 160,000 in the North West; a relatively remote geographic area and one of Ireland's poorest from a socioeconomic viewpoint. The region does not have GP access mammography and mammography can only be organized through attendance at a Symptomatic Breast Unit or through the breast screening service between the ages of 50 and 64 .

Patients entering the Breast Screening Programme were not included in this study. The enrolment rate for breast screening in Ireland is falling and now approaches $71.4 \%$ in line with other recruitments internationally. Of particular concern of those aged 50 - 54, invited for a first screening, 49.6\% in the West region accepted the offer [23]. The average lifetime risk of breast cancer is between $10 \%$ and $12.3 \%$ and the 10 -year risk of invasive breast cancer at the ages of 40,50 and 60 years are $1.5 \%, 2.3 \%$, and $3.5 \%$ respectively [26].

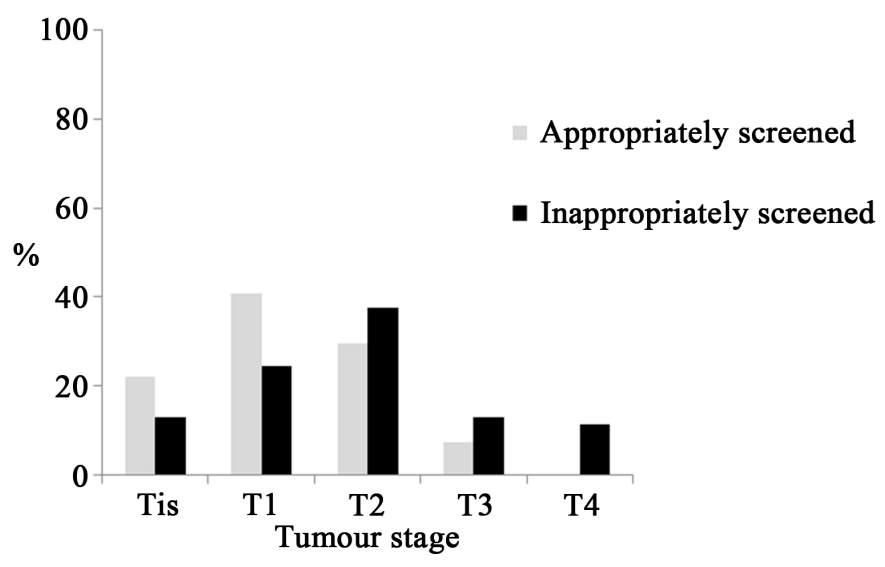

Figure 4. Tumour stages in those meeting screening criteria $(n=88)$. 
In our study the dominant symptom was a lump leading to the patients' presentation. $44 \%$ of our study population met criteria for breast screening, under international guidelines moderate to high risk patients should be screened [27]-[30]. Madlensky and colleagues (2005) have shown that moderate risk women have undertaken mammography in $47 \%$ of cases compared to $82 \%$ in high risk and $35 \%$ among the population risk [16].

There are many factors involved in failure to undertake mammography. These are patient and system related. Some are related to poor literacy, fatalistic fears and external decision making pressures [31]. Anxiety and stress also play a role [32]. New strategies to reduce the late presentation of breast cancer are considered important. Devi and colleagues [4] were able to reduce the prevalence of Stage III and Stage IV breast cancers from $60 \%$ to $35 \%$ by educating health staff on the theoretical and practical aspects of breast cancer and by strengthening public awareness programs and referral system for positive cases. Similarly in Singapore, Chang and colleagues found that up to $20 \%$ of patients were still presenting with Stage III and Stage IV breast cancer [33]. Surprisingly the stage and tumour size at presentation in this study was quite late with a mean invasive tumour size of 32 $\mathrm{mm}$ versus $35 \mathrm{~mm}$, and a significant over representation of stage III and IV and regional and metastatic disease in those failing to be risk assessed and screened.

Tabár and colleagues suggested that there was a $63 \%$ reduction in mortality in those screened and more recently Paap et al. found a 58\% reduction [34] [35]. Multiple individual studies, randomised controlled trials, meta-analysis and systematic review of the literature have challenged this. The Marmot report suggests there is a $20 \%$ reduction in mortality [11]. Pace and Keating suggests that this is $15 \%$ for women in their 40 s and $32 \%$ for women in their $60 \mathrm{~s}$. They have suggested that $19 \%$ of cancers diagnosed during the 10 year period would have become clinically apparent without screening and feel that this represents over diagnosis [26]. Others feel that over diagnosis is less of a problem at $0.7 \%$ in 40 to 49 years old [36]. Many studies have looked at delays, usually in the peri-operative period. A key National performance indicator [37] is that surgery occurs in over $90 \%$ of patients within 4 weeks of diagnosis, unless having neoadjuvant treatment. There were no significant perioperative delays; the median time to surgery was 12 days. It has been suggested that a delay of more than 6 months may affect outcome [38]. Others are showing that peri-operative delays had no impact on survival [39].

Patients presenting in this series were direct referrals to the Breast Unit and all but one of the patients were diagnosed on their visit following triple assessment. This compares with more economically challenged countries such as Mexico where 7.9 clinic visits were required before diagnosis [40].

Patient factors relating to failure to attend were not analysed and it is a limitation of the study. It was decided, despite ethical approval for this study, that it may have created an element of retrospective anxiety as to question the women as to why they had not attended for screening. A system problem with failure to recall patients before 2008 in 12 patients was deduced from auditing medical records; however at that time clear international guidelines were not as well developed in risk assessment. Currently the unit uses computerized and manual NICE guidelines for risk assessment [27] [41] [42].

International variation occurs in outcome from breast cancer across Europe, United States and other health areas. Stage has been felt to be one of the most dominant predictors of outcome [2] [3] [28] [43]-[45]. It is important to differentiate between adherences to mammography as a random or guideline event. In conclusion this study has identified that failure to risk assess and perform mammography in line with International current guidelines will result in delayed presentation of breast cancer. New strategies for risk assessment and screening in moderate risk patients need to be developed. Newer options in breast imaging may improve detection and outcome, but have not yet been validated [46] [47].

This study identified that women who failed to attend appropriate screening and risk assessment would have more advanced breast cancer. A public health review of enrolment and risk assessment process needs to be undertaken in the region.

\section{References}

[1] De Angelis, R., Sant, M., Coleman, M.P., et al. (2014) Cancer Survival in Europe 1999-2007 by Country and Age: Results of EUROCARE-5-A Population-Based Study. The Lancet Oncology, 15, 23-34. http://dx.doi.org/10.1016/S1470-2045(13)70546-1

[2] Barburin, A., Aareleid, T., Padrik, P., et al. (2014) Time Trends in Population-Based Cancer Survival in Estonia: Analysis by Age and Stage. Acta Oncologica, 53, 226-234. http://dx.doi.org/10.3109/0284186X.2013.806992

[3] Richards, M.A. (2009) The Size of the Prize for Earlier Diagnosis of Cancer in England. British Journal of Cancer, 101, S125-S129. http://dx.doi.org/10.1038/sj.bjc.6605402 
[4] Devi, B.C., Tang, T.S. and Corbex, M. (2007) Reducing by Half the Percentage of Late-Stage Presentation for Breast and Cervix Cancer over 4 Years: A Pilot Study of Clinical Downstaging in Sarawak, Malaysia. Annals of Oncology, 18, 1172-1176. http://dx.doi.org/10.1093/annonc/mdm105

[5] Friedman, L.C., Kalidas, M., Elledge, R., et al. (2006) Medical and Psychosocial Predictors of Delay in Seeking Medical Consultation for Breast Symptoms in Women in a Public Sector Setting. Journal of Behavioral Medicine, 29, $327-$ 334. http://dx.doi.org/10.1007/s10865-006-9059-2

[6] Mathis, K., Hoskin, T., Boughey, J., et al. (2010) Palpable Presentation of Breast Cancer Persists in the Era of Screening Mammography. Journal of American College of Surgeons, 210, 314-318. http://dx.doi.org/10.1016/j.jamcollsurg.2009.12.003

[7] Miller, A., Wall, C., Baines, C., et al. (2014) Twenty Five Year Follow-Up for Breast Cancer Incidence and Mortality of the Canadian National Breast Screening Study: Randomised Screening Trial. British Medical Journal, 348, g366g366.

[8] Bleyer, A. and Welch, H.G. (2012) Effect of Three Decades of Screening Mammography on Breast-Cancer Incidence. The New England Journal of Medicine, 367, 1998-2005. http://dx.doi.org/10.1056/NEJMoa1206809

[9] Tabár, L., Vitak, B., Chen, T.H., et al. (2011) Swedish Two-County Trial: Impact of Mammographic Screening on Breast Cancer Mortality during 3 Decades. Radiology, 260, 658-663. http://dx.doi.org/10.1148/radiol.11110469

[10] Biller-Andorno, N. and Juni, P. (2014) Abolishing Mammography Screening Programs? A View from the Swiss Medical Board. The New England Journal of Medicine, 370, 1965-1967. http://dx.doi.org/10.1056/NEJMp1401875

[11] Marmot, M. (2013) Sorting through the Arguments on Breast Screening. JAMA, 309, 2553-2554. http://dx.doi.org/10.1001/jama.2013.6822

[12] McCartney, M. (2014) A Trial to Extend Breast Cancer Screening May Be Unethical. British Medical Journal, 349, g5105. http://dx.doi.org/10.1136/bmj.g5105

[13] National Cancer Screening Service (NCSS) (2000) Breast Check-The National Breast Screening Programme. http://www.breastcheck.ie/

[14] Armstrong, A. and Evans, G. (2014) Management of Women at High Risk of Breast Cancer. British Medical Journal, 348, g2756. http://dx.doi.org/10.1136/bmj.g2756

[15] National Institute for Health and Clinical Excellence (2006) Quick Reference Guide. Clinical Guideline 41. Familial Breast Cancer: The Classification and Care of Women at Risk of Familial Breast Cancer in Primary, Secondary and Tertiary Care. NICE, London.

[16] Madlensky, L., Vierkant, R., Vachon, C.M., Pankratz, V.S., Cerhan, J.R., Vadaparampil, S.T. and Sellers, T.A. (2005) Preventive Health Behaviors and Familial Breast Cancer. Cancer Epidemiology, Biomarkers \& Prevention, 14, 2340 2345. http://dx.doi.org/10.1158/1055-9965.EPI-05-0254

[17] Price, M.A., Butow, P.N., Charles, M., Bullen, T., Meiser, B., McKinley, J.M., et al. (2010) Predictors of Breast Cancer Screening Behavior in Women with a Strong Family History of the Disease. Breast Cancer Research and Treatment, 124, 509-519. http://dx.doi.org/10.1007/s10549-010-0868-1

[18] Samphao, S., Wheeler, A.J., Rafferty, E., Michaelson, J.S., Specht, M.C., Gadd, M.A., et al. (2009) Diagnosis of Breast Cancer in Women Age 40 and Younger: Delays in Diagnosis Result from Underuse of Genetic Testing and Breast Imaging. American Journal of Surgery, 198, 538-543. http://dx.doi.org/10.1016/j.amjsurg.2009.06.010

[19] Narod, S., Valentini, A., Nofech-Mozes, S., Sun, P. and Hanna, W. (2012) Tumour Characteristics among Women with Very Low-Risk Breast Cancer. Breast Cancer Research and Treatment, 134, 1241-1246. http://dx.doi.org/10.1007/s10549-012-2065-x

[20] Health Service Executive. Galway University Hospitals Cancer Centre-Annual Report 2012. http://www.wnwhg.ie/sites/default/files/publications/cancer-centre-annual-report-2012.pdf

[21] IBIS Breast Cancer Risk Evaluation Tool. V6 2004. http://www.ems-trials.org/riskevaluator/

[22] AJCC (American Joint Committee on Cancer) (2010) Cancer Staging Manual. 7th Edition, Edge, S.B., Byrd, D.R., Compton, C.C., et al., Eds., Springer-Verlag, New York.

[23] National Cancer Screening Service (2014) Breast Check-Programme Report 2012-2013. Health Service Executive, Dublin. http://www.breastcheck.ie/sites/default/files/bcheck/documents/bc pr 2013.pdf

[24] Smith, R. (2014) Counterpoint: Overdiagnosis in Breast Cancer Screening. Journal of the American College of Radiology, 11, 648-652. http://dx.doi.org/10.1016/j.jacr.2014.03.011

[25] Hersch, J., Barratt, A., Jansen, J., Irwig, L., McGeechan, K., Jacklyn, G., et al. (2015) Use of a Decision Aid Including Information on Overdetection to Support Informed Choice about Breast Cancer Screening: A Randomised Controlled Trial. The Lancet, Published Online18 February 2015.

[26] Pace, L. and Keating, N. (2014) A Systematic Assessment of Benefits and Risks to Guide Breast Cancer Screening 
Decisions. JAMA, 311, 1327-1335. http://dx.doi.org/10.1001/jama.2014.1398

[27] National Institute for Health and Clinical Excellence (2013) Familial Breast Cancer: Classification and Care of People at Risk of Familial Breast Cancer and Management of Breast Cancer and Related Risks in People with a Family History of Breast Cancer. CG164. http://guidance.nice.org.uk/CG164/Guidance

[28] Møller, H., Sandin, F., Bray, F., Klint, Å., Linklater, K.M., Purushotham, A., et al. (2010) Breast Cancer Survival in England, Norway and Sweden: A Population-Based Comparison. International Journal of Cancer, 127, 2630-2638. http://dx.doi.org/10.1002/ijc.25264

[29] Anderson, E., Berg, J., Black, R., Bradshaw, N., Campbell, J., Carnaghan, H., et al. (2008) Prospective Surveillance of Women with a Family History of Breast Cancer: Auditing the Risk Threshold. British Journal of Cancer, 98, 840-844. http://dx.doi.org/10.1038/sj.bjc.6604155

[30] Gui, G., Hogben, R., Walsh, G., A’Hern, R. and Eeles, R. (2001) The Incidence of Breast Cancer from Screening Women According to Predicted Family History Risk: Does Annual Clinical Examination Add to Mammography? European Journal of Cancer, 37, 1668-1673. http://dx.doi.org/10.1016/S0959-8049(01)00207-6

[31] Taib, N., Yip, C. and Low, W. (2014) A Grounded Explanation of Why Women Present with Advanced Breast Cancer. World Journal of Surgery, 38, 1676-1684. http://dx.doi.org/10.1007/s00268-013-2339-4

[32] Schwartz, M., Taylor, K., Wilard, K., Siegel, J.E., Lamdan, R.M. and Moran, K. (1999) Distress, Personality and Mammography Utilization among Women with a Family History of Breast Cancer. Health Psychology, 18, 327-332. http://dx.doi.org/10.1037/0278-6133.18.4.327

[33] Chang, G., Chan, C. and Hartman, M. (2011) A Commentary on Delayed Presentation of Breast Cancer in Singapore. Asian Pacific Journal of Cancer Prevention, 12, 1635-1639.

[34] Tabár, L., Vitak, B., Chen, H., Yen, M.F., Duffy, S.W. and Smith, R.A. (2001) Beyond Randomized Controlled Trials. Cancer, 91, 1724-1731. http://dx.doi.org/10.1002/1097-0142(20010501)91:9<1724::AID-CNCR1190>3.0.CO;2-V

[35] Paap, E., Verbeek, A., Botterweck, A., et al. (2014) Breast Cancer Screening Halves the Risk of Breast Cancer Deaths: A Case-Referent Study. The Breast, 23, 439-444. http://dx.doi.org/10.1016/j.breast.2014.03.002

[36] Gunsoy, N., Garcia-Closas, M. and Moss, S. (2012) Modelling the Overdiagnosis of Breast Cancer Due to Mammography Screening in Women Aged 40 to 49 in the United Kingdom. Breast Cancer Research, 14, R152. http://dx.doi.org/10.1186/bcr3365

[37] HSE, NCCP Symptomatic Breast Disease. Key Performance Indicators: 3 Year Report 2010-2012. http://www.hse.ie/eng/services/list/5/cancer/pubs/intelligence/NCCP\%20KPI\%20report $\% 20$ symptomatic $\% 20$ breast $\% 2$ 0disease $\% 202010 \% 20-\% 202013 . p d f$

[38] Love, R., Duc, N., Baumann, L., Thi Hoang Anh, P., Van To, T., Qian, Z. and Havighurst, T.C. (2004) Duration of Signs and Survival in Premenopausal Women with Breast Cancer. Breast Cancer Research and Treatment, 86, 117 124. http://dx.doi.org/10.1023/B:BREA.0000032980.55245.c3

[39] Brazda, A., Estroff, J., Euhus, D., Leitch, A.M., Huth, J., Andrews, V., et al. (2010) Delays in Time to Treatment and Survival Impact in Breast Cancer. Annals of Surgical Oncology, 17, S291-S296. http://dx.doi.org/10.1245/s10434-010-1250-6

[40] Bright, K., Barghash, M., Donach, M., de la Barrera, M.G., Schneider, R.J. and Formenti, S.C. (2011) The Role of Health System Factors in Delaying Final Diagnosis and Treatment of Breast Cancer in Mexico City, Mexico. The Breast, 20, S54-S59. http://dx.doi.org/10.1016/j.breast.2011.02.012

[41] Gorman, A., Sugrue, M., Ahmed, Z. and Johnston, A. (2014) An Evaluation of FaHRAS Computer Programmes' Utility in Family History Triage of Breast Cancer. Advances in Breast Cancer Research, 3, 17-21. http://dx.doi.org/10.4236/abcr.2014.32004

[42] Thomas, J., Sugrue, M., Curran, S., Furey, M. and Sugrue, R. (2013) Are Family Doctors Compliant with Breast Family History Guidelines? Advances in Breast Cancer Research, 2, 149-153. http://dx.doi.org/10.4236/abcr.2013.24024

[43] Olesen, F., Hansen, R. and Vedsted, P. (2009) Delay in Diagnosis: The Experience in Denmark. British Journal of Cancer, 101, S5-S8. http://dx.doi.org/10.1038/sj.bjc.6605383

[44] Woods, L., Rachet, B., O’Connell, D., Lawrence, G., Tracey, E., Willmore, A. and Coleman, M.P. (2009) Large Difference in Patterns of Breast Cancer Survival between Australia and England: A Comparative Study Using Cancer Registry Data. International Journal of Cancer, 124, 2391-2399. http://dx.doi.org/10.1002/ijc.24233

[45] Sant, M., Allemani, C., Capocaccia, R., Hakulinen, T., Aareleid, T., Coebergh, J.W., et al. (2003) Stage at Diagnosis Is a Key Explanation of Differences in Breast Cancer Survival across Europe. International Journal of Cancer, 106, 416422. http://dx.doi.org/10.1002/ijc.11226

[46] Kopans, D. (2014) A New Era in Mammography Screening. Radiology, 271, 629-631. http://dx.doi.org/10.1148/radiol.14140177 
[47] Skaane, P., Bandos, A., Eben, E., Jebsen, I.N., Krager, M., Haakenaasen, U., et al. (2014) Two-View Digital Breast Tomosynthesis Screening with Synthetically Reconstructed Projection Images: Comparison with Digital Breast Tomosynthesis with Full-Field Digital Mammographic Images. Radiology, 271, 655-663.

http://dx.doi.org/10.1148/radiol.13131391 